\title{
EVALUACIÓN DE LA EFICACIA DE LA APLICACIÓN DE LAST PLANNER SYSTEM EN UN PROYECTO DE CONSTRUCCIÓN EN LA ETAPA DE ACABADOS - ARQUITECTURA EN PERÚ EN EL AÑO DE 2019
}

Maykol Miranda_Mejia, Esmeralda Torobisco_Vilca y Rosmery Gomez_Minaya

\section{RESUMEN}

En una ciudad emergente debido al dinamismo económico, con una capital que en los últimos años ha tenido un crecimiento demográfico agigantado, demanda proyectos inmobiliarios para satisfacer a los nuevos núcleos familiares. Como es el caso de los edificios multifamiliares de mediana envergadura, para los que se encontraron aplicaciones de nuevas metodologías como el Last Planner System que reduce los tiempos de ejecución. Para ello, el presente trabajo analiza, desarrolla e implementar mecanismos basados en la Filosofía Last Planner System, aplicados a un proyecto de edificación de 5 pisos, centrándose en las partidas de Acabados en un periodo de 5 semanas. Para completar esa cifra fue necesario crear 3 sectores luego se realizó un Plan Intermedio (Look Ahead Planning), posteriormente un Plan Semanal. En el presente estudio se implementó la metodología LPS en una obra de mediana envergadura a diferencia de otros estudios similares como el de (Miranda Casanova, 2012). Se concluye en el presente estudio de la aplicación del LPS a un proyecto mediano, es eficaz respecto a la mejora en los tiempos de ejecución con un valor de porcentaje de eficacia de 76 \% para la ejecución de las partidas de Arquitectura.

Palabras Clave: Acabados, Envergadura, LPS, Eficaz, Tiempo.

DOI: $10.23881 /$ idupbo.020.1-14i 